\title{
Collective Cultural Memory as a TV Guide: "Living" History and Nostalgia on the Digital Television Platform
}

\author{
Berber Hagedoorn \\ University of Groningen (NL) \\ E-mail: b.hagedoorn@rug.nl
}

\begin{abstract}
Modern audiences engage with representations of the past in a particular way via the medium of television, negotiating a shared understanding of the past. This is evidenced by the increasing popularity of reboots, newly developed history and documentary programming, re-use of archival footage and nostalgia content. This article takes a closer look at television's abilities to circulate and contextualize the past in the current era of convergence through narrowcasting or niche programming on digital television platforms, specifically via nostalgia programming. Such platforms exemplify the multifaceted way of looking at and gaining access to television programming through a variety of connected platforms and screens in the current multi-platform era. Since the way in which television professionals (producers, schedulers, commissioners, researchers) act as moderators in this process needs to be further analysed, the article places an emphasis on how meaningful connections via previously broadcast history and nostalgia programming are also curated, principally through scheduling and production practices for niche programming - key elements in television's creative process that have received less academic attention. Furthermore, the article discusses to what extent media policy in the Netherlands is attuned to the (re-)circulation of previously broadcast content and programming about past events, and reflects on television's possibilities for "re-screening" references to the past in the contemporary media landscape. The analysis is based on a combination of textual analysis of audio-visual archival content and a production studies approach of interviews with key professionals, to gain insight into the creators' strategies in relation to nostalgia programming and scheduling. Subsequently, the article demonstrates how national collective memory, as understood by television professionals in the Netherlands, informs the scheduling and circulation of "living history" on the digital thematic channel - collective cultural memory hence functioning as a TV guide.
\end{abstract}

Keywords: representing and re-screening the past, audio-visual and archival materials, multi-platform television, nostalgia programming and thematic scheduling, cultural memory. 


\section{Introduction}

In the current multi-platform era, modern audiences engage with representations of the past especially via the medium of television: on our connected screens, there is new history every day. Societies continuously negotiate a shared understanding of the past and television facilitates such negotiations (see Hagedoorn 2016; Holdsworth 2011; Hoskins 2004; Bourdon 2003; Edgerton and Rollins 2001). This is evidenced not only by the increasing popularity of newly developed history and documentary programming, but also by the growing appeal of reboots, nostalgia content and the re-use of archival footage. In this article, I take a closer look at television's abilities to circulate and contextualize the past in the current era of convergence through narrowcasting or niche programming on digital television platforms, specifically via nostalgia programming. ${ }^{1}$ Since the way in which television professionals (producers, schedulers, commissioners, researchers) act as moderators in this process needs to be further analysed, I place a particular emphasis on how meaningful connections via narrowcasting and scheduling of previously broadcast history and nostalgia programming are curated. Television plays a crucial role in experiences of time and space through scheduling. John Ellis has argued from this perspective that scheduling is the "locus of power in television" (2000, 25-26). More specifically, I analyse how national collective memory, as understood by television professionals, informs the scheduling of "living" history on the digital thematic channel.

To do so, I first relate the theoretical framework of cultural memory to the creation or construction of memory through practices of what I call "doing history," and reflect on television's possibilities for "re-screening” references to the past in our contemporary media landscape. I then zoom in on the role of television professionals as curators and the meaning of curated connections in the narrowcasting and scheduling of previously broadcast history and nostalgia programming. Here, I pay particular attention to key elements of television that have received a smaller amount of academic attention: the shaping of television content by distinct modes of interaction between television professionals through scheduling and production practices. A main Dutch digital thematic channel (the nostalgia thematic channel US, previously known as NostalgiaNet [in Dutch: ONS, previously NostalgieNet]) is discussed as a principal case study

1 This article is based on a part of chapter 4 from my dissertation: Berber Hagedoorn. 2016. Circulating History on Digital Platforms: Digital Thematic Channels. In Doing History, Creating Memory: Representing the Past in Documentary and Archive-Based Television Programmes within a Multi-Platform Landscape, 92-97, 103-112 and 162-165. 
to consider the creators' aims, strategies and conventions of circulating nostalgia and previously broadcast content on digital platforms on a textual and narrative level and a cultural-historical level, respectively. These platforms exemplify the multifaceted way of looking at and gaining access to television programming through a variety of connected platforms and screens. Finally, in this context on an institutional level, I pose the question to what extent Dutch media policy is attuned to the (re-)circulation of previously broadcast content, archival footage and programming about past events.

Media texts cannot be studied in isolation. This study is based on a textual analysis of a nostalgia thematic channel and its connected cross-media practices, as well as its creators' strategies in relation to nostalgia programming and scheduling. When one aims to understand how something works, it is necessary to gain insight into the aims and principles that the studied practices are rooted in - therefore I use the poetics of "doing history" as a research model for exploring the television practitioners' aims, strategies and conventions of contemporary representations of past events on a textual and narrative level, a cultural-historical level and an institutional level (Hagedoorn 2016, 24-33). More specifically, next to a textual analysis of the selected case study, I use a production studies approach to gain insight into the television creators' strategies of broadcasting and multi-platform storytelling in relation to past events and past television. I do so, principally, through semi-structured in-depth interviews with key professionals involved in the channel's production, research and online strategies, as well as key professionals involved in media policy in the Netherlands. Interviews with programme makers are a necessary part of constructing a poetics of doing history, to gain insight into the personal perspectives and vision of professionals regarding their work. As I have argued previously, such an approach can bring the creators' motives to the surface and help make power relations, as well as often implicit conventions explicit.

\section{Doing History, Creating Memory}

Memory is studied across different disciplines within the humanities and social sciences, such as media studies, history, literary studies, visual culture, art history, archaeology, film studies, philosophy, sociology and psychology, as well as (digital) memory studies. As a result, a wide range of concepts are used in its study and theorization: from digital memory (Hoskins 2017), collective memory (Halbwachs 1980), popular memory (Samuel 1994), social memory (Fentress and 
Wickham 1992) and lieux de mémoire (Nora 1989) to transnational memory (De Cesari and Rigney 2014) and transcultural dimensions of memory (Bond, Craps and Vermeulen 2017). This article zooms in on the notion of cultural memory, which distinguishes itself from the aforementioned concepts as a constructive process with a specific focus on the interplay of present and past in sociocultural contexts (Erll 2008). Hence, the emphasis in this article is on creating or constructing memory through practices of what I call "doing history." I follow the perspective of Marita Sturken, who argues that cultural memory is "memory that is shared outside the avenues of formal historical discourse yet is entangled with cultural products and imbued with cultural meaning" $(1997,3)$. Cultural memory is thus not oppositional to the discourse of official history, but rather "entangled" with it and calls attention to the active, continuous and unstable process of remembering - and therefore forgetting - in socio-cultural contexts. In this context, Liedeke Plate and Anneke Smelik have also defined cultural memory as the cultural dimension of memory, taken as both the what and the how that a culture remembers. Both these scholars understand remembering as a "tricky business:" "By remembering we form an idea of our self and shape a sense of our identity; thus, we end up embodying the memory that inhabits us. Yet, memory is a dynamic phenomenon for any individual, but also for a culture as a whole. Memory is affected by politics, ideology, technology, art and popular culture. By changing over time, memory may unsettle received ideas of the past and consequently of the present and even the future" (Plate and Smelik 2009, 1).

Cultural memory can thus be seen as the complex ways in which a culture remembers. The crucial role that media plays in the process of both remembering and forgetting is currently reaching new levels of interest in the interdisciplinary and multidisciplinary study of memory. I argue that it is especially the role of media professionals as curators of cultural memory that requires academic reflection. In this article, I will therefore pay specific attention to the television professionals' active role in the "re-screening" of the past in relation to collective memory and the repurposing of past television on contemporary platforms and screens.

Recent studies have pointed out the crucial role of media in not only the formation of cultural memory, but also in providing frameworks for remembering. Contemporary research therefore advocates a dynamic approach to the study of cultural memory and the media (Erll and Rigney 2009, 1-2; Van Dijck 2007, 16). Astrid Erll has stated that media and mediation need to be understood as a "switchboard" between individual and collective remembering: "Personal memories can only gain social relevance through media representation and 
distribution" $(2011,13)$. José van Dijck's study points to a similar function, describing media technologies as "tools that mediate between personal and collective cultural memory" $(2007,19)$. Drawing upon interdisciplinary memory research by Siegfried J. Schmidt, Erll and Rigney argue that media do not only mediate between a human being and the world as "instruments for sense-making," but also mediate between individuals and groups as "agents of networking" - and through both ways, create frameworks for shaping experience as well as memory $(2009,1)$. I advocate a similarly dynamic approach to the study of television today.

In the current multi-platform era, television can in this manner be studied as a practice of memory. Sturken has defined a practice of memory as "an activity that engages with, produces, reproduces and invests meaning in memories, whether personal, cultural or collective” $(2008,74)$. According to Sturken, the concept of cultural memory is profoundly connected to the notion of memory practices, because the active and constructed nature of memory is emphasized. The concept "practice of memory" also allows for a focus on television as a continuous, unstable and changing memory practice in the multi-platform era, particularly because the production and reconstruction of memory through cultural practices has as its basis the idea that memories are always part of larger processes of cultural negotiation and transformation. As Sturken argues: "This defines memories as narratives, as fluid and mediated cultural and personal traces of the past" (2008, 74; emphasis added).

Such a perspective was initially not given in the study of memory (see also: Halbwachs 1980) and is further problematized by the fact that electronic and digital media - television in particular - have been said to have a problematic or paradoxical relationship with history and memory. Susannah Radstone describes in her work Memory and Methodology that in the late twentieth century, experiences of immediacy, instantaneity and simultaneity inflected a crisis of memory in contemporary societies. The development of new media technologies was partly responsible for "deepening” this crisis, since such new media "collapse[d] the distance that previously separated an event from its representation” (Sobchack 1996, 5; Radstone 2000, 7). Thomas Elsaesser perhaps best explains this assumed paradoxical relationship between media, history and memory by arguing that the discourse of media memory - specifically for television - is "constitutively traumatic:" "The media images of television, regarded from the point of view of their referentiality, would [...] contribute to our cultural memory above all by preserving the traumatic nature of media-made history as post-history. [...] A past event, passed on in media images, is both 
un-dead and not alive. It is always exceeding, in whatever small and apparently insignificant way, the place and time, the status and hierarchy a historian might assign to it" (Elsaesser 2008, 409; emphasis added).

According to Elsaesser, then, historical events passed on in television images are always ready to return and never to be forgotten, but at the same time "interfered with, blurred, or overlaid by other images, other memories, other possible combinations and associations" and therefore also never quite remembered $(2008,409)$. In the current media climate, we are witnessing a vast growth of new media and digital technologies, new memory discourses and memory practices. The contemporary media landscape provides many opportunities for mediamade history as "post-history." Recent studies and international conferences have therefore started to discuss the considerable role of television today in the everyday process of remembering and forgetting. The current media climate is also uniquely suited to television as a practice of memory and its present role in the construction and circulation of cultural memory.

\section{Re-Screening}

In the current media landscape, televisual products and practices of re-screening add another multitude of possibilities for televisual references to the past. I use the concept of "re-screening" in its broadest sense, indicating the vast access to a (digital) repertoire of previously transmitted images in today's multi-mediated landscape. Televisual practices of re-screening repurpose previously broadcast images and archival footage (whether audio, video or photographic material), by positioning such images in a new historical and televisual context. A typical week of television viewing may include many instances in which the past is represented on television's connected screens and other platforms via practices of re-screening, such as the following forms of "televisual re-screening."

- Factual television: digital thematic channels and nostalgia networks; archivebased histories and documentary programmes, which repurpose archival images within a new context; news programming.

- Online television archives: the use of video-sharing websites or open media platforms by official archival institutions: to provide the general public with access to their archival collections, to contextualize said materials to make them usable and to stimulate creative re-use. Examples are newsreel archive British Pathé and the Netherlands Institute for Sound and Vision's use of the videosharing website YouTube, open media platforms offering online access to audio- 
visual images, such as Open Images (Open Images, http://www.openimages.eu/. en/); the growth of online television archives and cross-domain portals, such as Europeana (http://www.europeana.eu/portal) and EUscreen (http://www. euscreen.eu). ${ }^{2}$ These online and digital repositories offer opportunities for the creative re-use of audio-visual archival materials, as well as for reflections on rights issues related to the re-use of audio-visual material in the digital era.

- Museum experiences: "re-screening" as a museum experience or tourist attraction for the public, which employs contemporary strategies of museum exhibition appealing to nostalgia. Such developments are part of (television) archives providing greater access and utilization of audio-visual materials, not only in the archive itself, but also through multimedia public facilities. Examples are the Netherlands Institute for Sound and Vision's Media Experience in Hilversum, the National Media Museum in Bradford and the Doctor Who Experience in Cardiff Bay.

- On-demand (online and streaming) services; repeats: on-demand (online and streaming) services, access to "missed" television programmes via catchup TV services and the scheduling of repeats, including acclaimed and popular television series from an earlier era. For example, the aggressive multi-million bidding war for Seinfeld's streaming rights to its 180 episodes was ultimately won by Hulu (Stelter 2015).

- Highlight reviewing: the activity of reviewing "must-see" televised moments and events in the form of short clips or compilations, whether from one programme or a variety of programmes, which serve different functions in different contexts. Think of informative programmes, talk shows and quiz shows and features of the traditional television series such as the "previously on..." overview often used in fictional series, which reminds viewers of important proceedings. This category also included video-sharing sites, web pages and social media sharing video content "that should not be missed" - including classic clips from the archives.

- Televised celebrations, commemorations and anniversaries: television events, which assemble and recycle previously aired television images, in both a national and international context, for reminiscence or reflection; this also includes anniversaries of the television's own history and reflections on the television's own past, accompanied by "making-of" or "behind the scenes" production footage. In this context, Amy Holdsworth (2010) has also discussed the necrology as a form of televisual memory.

- DIY TV archiving: the rapid advance of "Do-It-Yourself” television archiving or "home modes" of collecting and increased personalization, such as via

$2 \quad$ Last accessed 13. 10. 2017. 
digital television recorders, the purchasing of television series on DVD and the increased individual access to television archives curated by Netflix or Amazon Prime through monthly subscriptions. This also enhances the importance of including the use of video-sharing websites by private citizens to distribute and discuss television memories. Lynn Spigel $(2006,343)$ has described this trend as "Do-It-Yourself TV history," but in my view "DIY archiving" is a more accurate description of such at-home forms of collecting.

- Mobile telephony and gaming experiences: mobile telephony and gaming experiences of re-screening that stimulate recollection and creative re-use of audio-visual archival material in televisual contexts. For example, the Dutch video labelling game Waisda? ? $^{3}$ asked players to add tags to previously aired television footage in an innovative annotation game, resulting in a better ability to search audio-visual archives.

- Retro television and countdown television: programming, which constructs a storyline around clips from the television's past. Interviewees (often celebrities) give the impression to be recalling a specific moment in time in these programmes, but have often been informed to talk about a specific programme or have been sent a tape to watch in advance. Therefore, this type of programming is most inclined to represent a kind of "fake" nostalgia compared to the aforementioned trends.

- Reboots and remakes of celebrated television programmes: the increased reviving or rebooting of celebrated television programmes as remakes: such texts reappear as television remakes, but also re-emerge in different media formats. Think of the revivals of Yes, Prime Minister (UKTV Gold, 2013), Doctor Who (BBC, 1963-), Upstairs Downstairs (BBC, 2010-2012) and Poldark (BBC, 2015-), the reboot of Heroes (as Heroes Reborn on NBC, 2015-16) and follow-ups to 24 (as 24 Legacy on Fox, 2017), Twin Peaks (Showtime, expected to air in 2017), The X-Files (FOX, 2016) and Full House (as Fuller House, Netflix 2016-) to the updating of run-down formats like Big Brother (in the Netherlands on Veronica/ RTL5, 1999-2008) through recent reincarnations like I Survived a Zombie Apocalypse (BBC, 2015) and Utopia (in the Netherlands on SBS6, 2013-).

- TV review platforms: websites such as The A.V. Club and TV.com which feature amongst others detailed episode guides and television show descriptions, user commentary and discussions, videos, cast and crew listings, as well as (live) talk shows and podcasts dedicated to reviewing television shows, for instance the TV talk show Talking Dead (AMC, 2011-) and the Talking Dead podcast (both made by different creators), both dedicated to reviewing and reflecting on AMC's 
The Walking Dead. Such platforms usually encourage active user participation, as well as the inclusion of user-generated content.

These principal examples or prototypes of televisual re-screening - and please note that this list is not exhaustive ${ }^{4}$ - on the one hand repurpose previously transmitted and archival images, and on the other hand memorialize the history of television. Several of these practices are not necessarily new - such as the collecting and recording of television programmes, or the use of archival materials in television documentaries - which makes it even more striking to witness how televisual forms of re-screening have gradually been further integrated in both existing and new media practices. Users in modern societies are becoming more and more used to fast and easy access to such a (digital) repertoire. However, intellectual property rights may also restrict this repertoire, including copyright and related rights; for instance, a platform like YouTube contains a considerable amount of infringement that is a challenge to curtail, to say the least. Furthermore, more traditional aspects like the "previously on..." overview often used in fictional series, which reminds viewers of important proceedings can be absent in on-demand streaming content, for instance by providers such as Netflix and Amazon Prime, the programming of which is designed for binge-watching. Television's continuing convergence is therefore not only actively recirculating several of these forms of televisual re-screening, but in some cases, is also actively replacing or removing them in the current multi-platform era.

\section{"Living" History and Collective Memory on the Digital Thematic Channel}

Milly Buonanno has argued that the rise of a, albeit diffused, social demand for made-to-measure television adapted to the niche market ("the specific preferences and interests of a restricted number of viewers"), has also made narrowcasting possible $(2008,22-25)$. Buonanno describes narrowcasting as specialized or thematic television, as well as "the proliferating system of minority channels and small cable and satellite networks available on subscription" $(2008,22-25)$. What is more, her work has pointed out that "generalist" broadcasting networks are clearly not in a position to satisfy such a social demand. The scheduling on digital thematic channels demonstrates, as I have argued elsewhere, how television professionals working in such thematic forms of television actively

$4 \quad$ We see these types of re-screening and appeals to nostalgia and memory in other media as well of course, such as for instance in film - e.g. in T2: Trainspotting (2017). 
participate in practices of selection and reframing, that way creating a "canon." Scheduling in the context of a digital thematic channel can be compared to the work of a curator - a knowledgeable "selector" of content - due to the emphasis on pre-selection (Hagedoorn 2013, 61).

A further analysis of the Dutch commercial digital thematic channel ONS/ NostalgieNet (http://www.kijkbijons.nl, last accessed 13. 10. 2017.) can show the crucial role played by programme makers in the construction and circulation of living history in the multi-platform era, and the role of national collective memory in the creative act of scheduling on the digital thematic channel. ${ }^{5}$ Drawing upon a variety of archives and archival materials from the 1940s through the 1990s, the channel rebroadcasts popular Dutch television drama series and films and produces its own nostalgia programmes. This commercial channel is part of the standard package of leading suppliers of digital television in the Netherlands. From its start in 2006, NostalgieNet catered to its audiences as a cross-media platform and functions as a dynamic multi-platform archive through its video on-demand service. The NostalgieNet cross-media platform included a web shop, magazine, website, newsletter and interactive services on Facebook and Twitter - including modest possibilities of "co-authorship" regarding its own programming, meaning that viewers could use Facebook applications to create their own list preference, for example regarding music programming, which would then also be applied to the programming you would see on television. This cross-media content has not remained actively available as a long tail (even before NostalgieNet became ONS) and offered opportunities for the formation of a "participatory memory" (Hagedoorn 2015) during a limited period of time.

The programming is targeted towards a more senior audience between fortyfive to sixty-five years old - a group, which also very much wants to be taken seriously on social media - and is also valued by younger viewers as cult programming. The channel features a large variety of programming, from fictional films and television drama series (classic films, as well as so-called "forgotten gems") to non-fiction nostalgia programming, national as well as regional topics and interests, colour and black-and-white footage, generally between 1940-1990, although archival materials used from the Dutch Polygoon newsreel archive can date back to 1929. Its narrowcasting thus targets diverse audience groups.

5 In comparison, see my analysis of the former cross-media documentary platform of Dutch public television, NPO Doc/ HollandDoc. In this case, the hybridity of the platform was made visible through the dispersed access to a wide range of programmes on different platforms through cross-platform scheduling, including traditional broadcast television and radio, as well as online forms (Hagedoorn 2013). 
This "resurrection" of archived television for public consumption exemplifies what has been described as the clear marking of the currency of television memory and nostalgia, and the exploitation of the broadcasters' "sleeping assets" (Holdsworth 2010) - although there are some conditions here, which I will discuss later. From the $13^{\text {th }}$ of September 2015, NostalgieNet has become ONS [US]. Like NostalgieNet, ONS opts for a target group of active senior citizens with a lot of spare time. The programming enhances travel, nature, culture, history, nostalgia, health and food, entertainment, drama and Dutch films. The scheduling also includes well-known television series from the 1990s appealing to Dutch collective memory, such as Absolutely Fabulous (BBC, 1992-2012). New programmes include, for example, De Gouden Jaren (The Golden Years) (ONS, 2015-) involving modern history. Whereas NostalgieNet had a four-hour programming schedule, ONS consists of daily horizontal programming times with similar interests. The analysis of scheduled television programmes and curatorial practices and experiences brought several insights to the foreground regarding the digital television platform's main tools and methods for curating, programming and promoting "nostalgia."

Discussions with creators Cees Labeur ${ }^{6}$ and Tim Beudel ${ }^{7}$ (personal interview, Hilversum, 27 November 2012) point to programming on the platform following three basic rules or preconditions. These preconditions further restrict what Derek Kompare has called "regimes of repetition" $(2002,19)$. Holdsworth has pointed out regimes of repetition as a useful starting point to investigate the construction of and engagement with television's own memory cultures, as such regimes entail the constant (re-)circulation of a nation's individual and cultural pasts, through the omnipresence of past television in the present $(2007,140)$. First and fundamentally, as the discussions with the nostalgia platform's creators make apparent, nostalgia here is contemporary history - what the creators term

$6 \quad$ Cees Labeur started his career in 1969 as a journalist for Elsevier Magazine. In 1977, he switched to Hier en $\mathrm{Nu}$ (Here and Now), a current affairs programme at NCRV television. He was a television reporter in the Netherlands and abroad and was one of the regular interviewers at the weekly press conference with the Prime Minister. In 1995, he was one of the initiators and general editor of Netwerk (Network), a combined current affairs programme of KRO, NCRV and AVRO. Until 2007 he was television manager of informative programmes at NCRV, including Rondom Tien (Around Ten), Dokument (Document), Man Bijt Hond (Man Bites Dog), De Rijdende Rechter (The People's Court) and Netwerk. From 2007 until January 2015, he was responsible for the programming of the digital television channel NostalgieNet.

7 Tim Beudel studied Communication Studies at the Universiteit van Amsterdam (University of Amsterdam). In 2005, he joined NostalgieNet, managing different platforms and revenues; TV, VOD, e-commerce, print and online. From August 2013, he was Head of Digital at Tuvalu Media. Tuvalu Media creates and produces cross-media concepts. Since September 2017, Beudel is Channel Director of National Geographic Benelux. 
"living" history - and in this manner appealing to the collective memory of a nation, which in this case is the Dutch nation.

The platform emphasizes nostalgia as "living" history (not to be confused with the term used for historical re-enactment practices!). What is referred to here is that important events, years and dates connected to national collective memory and from Dutch contemporary history are the incentive for its scheduling. For example, televised media events, such as Reinier Paping winning the Dutch Elfstedentocht (eleven-city skating race) in 1963 or The Beatles' arrival in The Netherlands in 1964 and people's memories of such events. The platform aims to "bring the past alive" via emotion and sharing with others. This is a significantly different approach to the "exploitation" of television's own history and the engagement of audiences with archival footage than the "regular" history programming of public service broadcasters re-using archival footage.

NostalgieNet utilizes different multi-media platforms and methods to facilitate the enhancement of emotion for their niche target audience. This is done by offering nostalgic programming using archival footage in which people can recognize their own childhood, their own father, their own mother or sometimes themselves as a child. Not in a literal sense, although there have been instances, where people actually did recognize themselves or a family member on television. This strategy is further intensified by the platform by offering crossmedia possibilities to let viewers share their favourite fragments of the past. The NostalgieNet cross-media platform included a web shop, magazine, website, newsletter and interactive services on Facebook and Twitter. There were mild possibilities for co-authorship regarding the platform's own programming here, since viewers could use Facebook applications to create and share their own lists of preferences - for example in the case of music programming - which could then be considered for the scheduling on television.

This form of living history adheres to feelings occurring when watching a programme for the first time, and also to television as a shared experience. This digital thematic channel wants to achieve both, through the selection and through contextualization of archival content, and by making meaningful connections through a cross-media strategy. Its creators regard nostalgia as emotion, as something different from historical facts, and this emotion makes sharing and shared experiences possible. As a niche channel, the platform aims to bring people together based on their own interests regarding their own past, to create a collective feeling of "I remember that!" Whether these are shared interests in 
music or hobbies, this strategy advocates bringing people together using nostalgia as a common denominator. This is explained by the creators as follows:

Beudel: History is factual, nostalgia is emotional. And that emotion also makes it easy to share. You cannot very easily share on television, but you can do so on the internet and other devices, such as a mobile etcetera. So, our intent, for television and the internet, was to bring people together based on the interests of their own past. And that could be: 'I went to school here,' or 'I had a Zündapp, or a Puch, for a motorbike...' and then you can form a small group around such a shared interest.

Labeur: Or around 'I liked The Beatles...'

Beudel: Yes, you can bring people together using the nostalgia of a given music, interests or hobbies, as a common divisor. But then you must go the multi-media route too. So that was very important in our vision and that is one of the reasons we took a multi-media approach from the outset. (personal interview, Hilversum, 27 November 2012.)

This approach to nostalgia as emotion can therefore be directly linked to the platform's initial multi-media approach to storytelling and the perspective on television, internet, DVD, video on demand (in an early form) and mobile telephony as media that can enhance one another - especially during a period, when Dutch broadcasters were actively developing and experimenting with new cross-media storytelling techniques.

Secondly, the nostalgia platform's approach to living history is a light or entertainment approach to history - although not necessarily superficial. A light approach includes that the platform deliberately does not want content to be too heavy-hearted, and places a focus more on personal and emotional impact instead of historical impact, often through oral history. For instance, a programme about the pirate radio station and ship Veronica would include interviews with people about their memories, how this experience felt and what it meant at the time. However, such a programme would not try to answer questions like what this meant for Dutch television scheduling or for the Dutch broadcasting system as a whole, as other historical programmes perhaps would.

Here, I would like to point towards the contemporary flourishing of "nostalgia" as a commercial and marketing strategy in line with an increased academic reflection on "nostalgia" as a more complex notion that is valid of critical reflection from historical, sociological, political, economic and aesthetic 
perspectives (Niemeyer et al. 2014, 6 and see also Boym 2001). NostalgieNet's light or entertainment approach to nostalgia as living history is a significantly different approach to "nostalgia" as a strategy for the seemingly comparable Russian niche channel Nostalgia that started broadcasting in 2004. Nostalgia's own approach to nostalgia is targeted towards offering a clearer narrative of the Soviet past and towards its viewers becoming more knowledgeable about this past. Hence in this case, as Ekaterina Kalinina (2014) demonstrates in her analysis of the platform, because "nostalgia" is an emotion, which urges users to go back to the past, it can be experienced as such by Nostalgia's users, but is not part of the programmed content. Rather, Nostalgia's scheduled content fosters an analysis of the past, and as editor-in-chief Michael Galich states "where the past is discussed, then it is not nostalgia any longer" (Kalinina 2014, 117). Examples like Nostalgia and NostalgieNet therefore demonstrate the relevance of case study analysis to point out and allow space for different production perspectives on nostalgia, as well as necessary critical reflection on nostalgia as a complex and multi-faceted notion.

Third and finally, the programming generally does not go further back than 1940-1950. On the one hand, this is quite logical, as there is not much television material before that time. On the other hand, this goes for topics as well because of the platform's appeal to collective memory and living history. Therefore, no programmes about the Middle Ages and the like. This strategy has more recently been expanded, so not only to include Dutch programming, which follows the mentioned preconditions, but also programming, which many Dutch people remember, such as The Onedin Line (BBC, 1971-1980) with its memorable television theme tune, and All Creatures Great and Small (BBC, 1978-1990) (titled James Herriot on the thematic channel, because of how the Dutch remember this programme). 'Allo 'Allo (BBC, 1982-1992) and Absolutely Fabulous (BBC, 1992-2012) are other examples, although these are not Dutch programmes, they do appeal very much to Dutch collective memory. Scheduling on the NostalgieNet platform therefore reflects a specific assumption regarding national (Dutch) collective memory.

The analysis of the scheduling on the nostalgia platform reveals how television professionals actively participate in practices of selection and reframing, that way creating a canon. Scheduling in the context of a digital thematic channel can be compared to the work of a curator. The channel provides access to history programming by functioning as a "thematic periodical" (Müller 2012, 290), based on a selection of topical as well as recurring themes. For example, the series Nederland Toen, freely translated as "that's how it was in the Netherlands," pays 
attention to how Holland has changed in the twentieth century. The series looks back at everyday life through topics that are recognizable for a large audience, from fashion to sports through household activities to industry. Monthly themes can be based on an anniversary (for instance, Liberation Day) and commemoration (for instance, Dutch East Indies), but also on typical events connected to a specific time of the year. Examples are programmes about the Royal Family in April, variety around Christmas, and the weather is an often-featured theme in January since in the words of Cees Labeur "Dutch people love talking about the weather." Within a flow of 24/7 programming, previously broadcast images and audiovisual archive materials are repurposed and further enhanced by positioning these images in new historical and televisual contexts.

To make sense of all the available archival footage, ordering in formats and contextualization is necessary. For instance, archival footage will be juxtaposed and provided with a new voice-over narration. Selected programmes for the "canon" are (re-)framed and contextualized to offer television users a better understanding of the selected texts. The pacing and timing of the schedule is also important, because the channel often offers counter programming. Furthermore, because the acquisition of programmes takes time and scheduling is devised to join with important events and dates, scheduling is planned well in advance - I have also called this a "ritualized" form of actuality (Hagedoorn 2013, 61).

Finally, as a precondition, next to the creators setting limitations for what kind of content their niche audience will have access to, there are also some difficulties in gaining access to Dutch public broadcasters' archives. This specifically concerns the issue of kannibalisering ("cannibalizing”). For example, if ONS/ NostalgieNet as a commercial channel would be able to schedule a 1960s hit programme, such as the drama series De Kleine Waarheid (Everyday Life [NCRV, 1970-1973]) produced by Dutch public broadcaster NCRV, and this series would then be scheduled against current NCRV programming, the public broadcaster would have to compete against itself. As a result, there is plenty of televisual content still on the shelf, which historical and nostalgia thematic channels would very much like to broadcast and share with their audiences. Subsequently, the case of ONS/ NostalgieNet helps to clarify how national collective memory - or more specifically, national collective memory as understood by television professionals - affects the scheduling of living history on the digital thematic channel. 


\section{Media Policy in the Netherlands}

To what extent is media policy in the Netherlands attuned to the circulation of nostalgic television content discussed above? On a regular basis, the Ministry is in contact with the managing directors of radio and television producers in Hilversum. The Ministry of Education, Culture and Science must comply with the Audiovisual Media Services (AVMS) Directive set out by the European Parliament and the European Council ("Television without boundaries"). This Directive establishes legal, regulatory and administrative provisions related to the distribution of audio-visual media services. Amongst others, media service providers must fulfil certain obligations, including:

- broadcasters must devote at least $10 \%$ of their transmission time, or $10 \%$ of their programming budget, to European works created by producers who are independent of broadcasters, excluding time allocated to news, sports events, games, advertising, teletext services, teleshopping;

- regarding on-demand audio-visual media services, EU countries shall ensure that audio-visual media service providers promote the production of and access to European works;

- protection of minors;

- the right to information: EU countries may take measures aimed at ensuring that certain events, which they consider to be of major importance for society, cannot be broadcast exclusively in such a way as to deprive a substantial proportion of the public in that EU country (Audiovisual Media Services [AVMS] Directive, $2015^{8}$ ). The AVMS Directive prescribes a majority of broadcast time to European works, and for the Netherlands this is 50\% (Cees van Koppen, personal communication, 15 November 2017).

Each EU Member State has its own procedures. The question is what kind of broadcasting system is to be set out in the Netherlands. New regulations are implemented in the new Media Act, for instance regarding the extent in which commercials and entertainment are broadcast on the public channels.

Television is becoming more and more significant on European and international levels. Copyright and royalties may become an issue, since legislation is regulated per country. In the contemporary televisual landscape, more foreign content is available on Dutch television. More and more radio and media service providers are also owned by companies from abroad. There are broadcasters, who

8 See: http://eur-lex.europa.eu/legal-content/EN-NL/ALL/?uri=URISERV:am0005. Last accessed 22. 09. 2015. 
immediately break into new techniques, but offer no new services as such. In the Netherlands, new applications must gain the approval of the Ministry. They need to be agreed upon by the different radio and television broadcasters and their managing directors or boards - decision making therefore takes time.

As Cees van Koppen, former Policy Advisor at the Ministry of Education, Culture \& Science Department of Media and Creative Industries argues (personal interview, The Hague, 9 November 2012), the strength of the Dutch system is being multiform. From the year 2016, the new Media Act offers opportunities for television producers from "outside" the NPO to submit programmes. Furthermore, the NPO will become increasingly independent. However, the responsibility of the NPO remains unchanged. The core business of the Dutch public broadcasting system remains the focus on education, information and culture, with programmes suitable for all sections of society. Performance agreements determine that a programme should reach about $85 \%$ of the Dutch viewers. If the NPO was to focus on one type of programming, this target would become out of reach and, amongst other things, revenues from advertisers would drop (source: Cees van Koppen, personal interview). The Dutch Media Authority (Commissariaat voor de Media [CvdM]) upholds the rules, which are formulated in the Dutch Media Act, as well as in the regulations based on this act, for example the Media Decree. Despite some initial fears, viewers will not be deprived of entertainment. The newly adopted Media Act brings considerable changes by bidding that public broadcasting must be open to outside producers, entertainment is not a core task anymore and the NPO will gain more power, with influence on content. ${ }^{9}$

In their 2006 policy plan, the NPO foresaw an increase in the use of different channels by the public. Their plan was to expand the public broadcasting portfolio by offering thematic channels via subscription television, which would cover themes more in-depth. The three open public channels would serve more as "shop windows" to guide viewers to the thematic channels and on-demand platforms (NPO $2005,11)$. The thematic channels and on-demand platforms via the internet would be the pivot in the NPO's cross-media strategy, which was primarily aimed at guiding viewers to content on the different media platforms (NPO 2005, 45). An important challenge in this development regarding the use of archival footage in television

9 See: De Volkskrant redactie. BN'ers roepen Kamer op om tegen Mediawet te stemmen, de Volkskrant. http://www.volkskrant.nl/media/bn-ers-roepen-kamer-op-om-tegen-mediawet-testemmen a4162176/.

De Volkskrant redactie. Nieuwe Mediawet met ruime meerderheid aangenomen [New Media Act Adopted by a Large Majority] de Volkskrant. http://www.volkskrant.nl/media/nieuwemediawet-met-ruime-meerderheid-aangenomen a4162391/. Last accessed 13. 10. 2017. 
programming was to obtain copyright and licence fees to use this footage, not only for one broadcast on linear television, but also for recurrent broadcasts on thematic channels and on-demand distribution via the internet (Nuchelmans 2014, 33). Not only are these licence fees higher, but also there are myriads of rights holders, who are often difficult to locate (see for instance Korteweg and P. B. Hugenholtz 2011).

However, since the early 2010s the public broadcasting system has seen increasing budget cuts, and was forced to organize itself more efficiently. From 2010 onwards, digital thematic channels and websites would be reduced, and the remaining channels would be more focused and more recognizable (NPO 2009, 2010). Websites needed to have a clear link to the broadcasters' scheduling on other channels. From 2016 onwards, the new policy plan for the NPO has taken effect (see also NPO 2015b). The emphasis in the next five years will be on a greater focus in themes and broadcasting platforms. Driven by financial cutbacks, the number of thematic channels and websites will be reduced and the web content will be centralized. In contrast to the previous five-year policy period, "history" will not be one of the main themes around which programmes are developed. An added complication concerning a greater focus on on-demand television is that rightful claimants of programme copyrights - especially in the case of archival materials - need to be tracked down and financially compensated. Consequently, only archival materials and websites of programmes that are actively broadcast will be available online on the NPO website. The broadcast material of past programmes will be moved to the Netherlands Institute for Sound and Vision archive, which will become online and will be made available. While websites for "strong brands" that have considerable public value and reach a large audience - for instance, the programme website of the history series Andere Tijden (Changing Times [NPS/NTR/VPRO, 2000-], http:// anderetijden.nl Last accessed 13. 10. 2015.) - will specifically be expanded and function as portals for dissemination of archival and contextual materials, context materials like programme websites for past programmes will be discontinued. However, contextualization and infrastructure are key preconditions for users of audio-visual archival materials (including television audiences, media researchers and media professionals), not least to find their way through the enormous amounts of materials; and media policy also further complicates the re-use of audio-visual materials (see also Hagedoorn and Agterberg 2016).

In May-June 2015, news filtered through that the NPO was to reduce the number of programming websites drastically and some broadcasters, like NPO $D o c$, would even be disbanded. Broadcasters and audiences reacted lividly, as evidenced by numerous reactions on websites (NPO Doc Homepage, 16 June 
2015). ${ }^{10}$ In the new Media Act, broadcasters will maintain self-governing within the NPO and keep their own identity. The focus of NPO policy in the period 2016-2020 will also concern a more integral programming of broadcasts to connect and interact with audiences, meaning a multi-platform strategy to offer broadcasts that are in line with how audiences are estimated to watch television.

This poses questions in relation to how the success of narrowcasting and contextualization practices for smaller and fragmented niche audiences is measured, especially for those specialized audiences that value linear television viewing. This is even more complicated in the multi-platform era, where television content is dispersed across numerous platforms and screens - and hence, more dynamic and complex to evaluate.

\section{Creating Meaning: Curated Connections via Nostalgia Scheduling and Narrowcasting}

The trend of individuals watching a television programme when it is most convenient for them undermines the traditional system of channels and broadcasting companies. Public service broadcasting in the Netherlands traditionally revolves around carefully structured programming and broadcasting schedules devised by network managers persuading viewers to tune into programmes they would perhaps not spontaneously watch. Since the analogue switch-off, legislature regarding digital channels and the general digitalization of society, the NPO has seen a sharp increase in the number of digital thematic channels and websites. In this article, I have considered the role of television professionals as curators and the meaning of curated connections in the scheduled "re-screening" of previously broadcast history and nostalgia programming on the digital thematic channel. I have interpreted my selected case materials within the theoretical framework of cultural memory, understanding memory as a constructive process with a specific focus on the interplay of present and past in socio-cultural contexts (Erll 2008). The discussion of the commercial thematic channel ONS/ NostalgieNet provides an insight into the scheduling from (national) collective memory, as well as more present-day issues, such as the exploitation and cannibalization of archival footage. A reflection on the extent in which media policy in the Netherlands is attuned to the current (re-)circulation of previously screened content has finally raised questions in relation to how the success of narrowcasting and contextualization practices for fragmented niche audiences is measured in the multi-platform era.

10 See: http://www.npodoc.nl/nieuws/2015/reageer. Last accessed 16. 06. 2015. 
The analysis points out the crucial role played by programme makers in the construction and circulation of nostalgia in the multi-platform era, and the role of national collective memory in the creative act of scheduling on the digital thematic channel. Programming and scheduling on the analysed platform takes a thematic (rather than kaleidoscopic) approach to nostalgia content and follows three basic rules or preconditions: (1) nostalgia as contemporary history or "living" history, appealing to the collective memory of the Dutch nation; (2) a light or entertainment approach to history, although not necessarily superficial and (3) because of this appeal - and in a lesser context, practical availability of audio-visual archival content - the programming generally does not go further back than 1940-1950. The creators have also set out to further enhance this strategy by means of multi-media modes of storytelling in relation to scheduled content. These three preconditions further restrict what Kompare has called "regimes of repetition" $(2002,19)$. It helps to clarify how national collective memory - or more specifically, national collective memory as understood by television professionals - affects the scheduling of living history on the digital thematic channel. Important events, years, and dates connected to national collective memory and from Dutch contemporary history are the incentive for its scheduling, and this strategy can be further intensified by cross-platform techniques. The platform ultimately regards nostalgia as emotion (something very different than historical facts) and aims to "bring the past alive" via emotion and sharing with others. This form of living history adheres most to feelings occurring when watching a programme for the first time, and to television as a shared experience. This digital thematic channel aims to achieve both, through their programme selection and through contextualization of archival content.

This brings new challenges for the online circulation of audio-visual (archival) materials. The increasing budget cuts and recent media policies in the Dutch public broadcasting system affect the production and online presentation of programmes on digital thematic channels, their related cross-media practices, and ultimately, the function of online circulated material as material for contextualization and memory construction - collective cultural memory as a TV guide. However, the dynamic production and scheduling practices studied in this article offer specific opportunities for niche audiences to engage with the past. Television in this manner can play an important role as a "history teacher" in present-day society. Not only does television achieve this through the scheduling of nostalgia programmes and by telling stories from the past, 
but also by making materials from archives accessible on diverse platforms and contextualizing them for specific audiences $24 / 7$.

In the current media landscape, televisual products and practices of re-screening add another multitude of possibilities for televisual references to the past, through access to the vast - largely digital - repertoire of previously transmitted images. Televisual practices of re-screening signify less the repurposing or borrowing of "a 'property' from one medium and [the] re-use [of] it in another" (Bolter and Grusin 1999; see also Jönsson 2008). It is apparent that the circulation of television materials is no longer limited to the television set itself, as television today is part of a much wider culture of circulation and more distinct cultures of television viewing. Instead, contemporary televisual practices of re-screening contain the integration and adaptation of past television and audio-visual archive materials in a new context of television itself.

\section{References}

Bond, Lucy; Stef Craps and Pieter Vermeulen, eds. 2017. Memory Unbound: Tracing the Dynamics of Memory Studies. New York: Berghahn Books.

Boym, Svetlana. 2001. The Future of Nostalgia. New York: Basic Books.

Bolter, Jay David and Richard Grusin. 1999. Remediation: Understanding New Media. Cambridge, MA: MIT Press.

Buonanno, Milly. 2008. The Age of Television: Experiences and Theories. Bristol: Intellect Books.

Bourdon, Jérôme. 2003. Some Sense of Time: Remembering Television. History and Memory vol. 15, no. 2: 5-35.

De Cesari, Chiara and Ann Rigney. 2014. Transnational Memory: Circulation, Articulation, Scales. Berlin: De Gruyter.

Dijck, José van. 2007. Mediated Memories in the Digital Age. Stanford, CA: Stanford University Press.

Edgerton, Gary R and Peter C Rollins, eds. 2001. Television Histories: Shaping Collective Memory in the Media Age. Lexington, KY: University Press of Kentucky.

Ellis, John. 2000. Scheduling: The Last Creative Act in Television? Media, Culture and Society vol 22, no. 1: 25-38.

Elsaesser, Thomas. 2008. History, Media, Memory - Three Discourses in Dispute. In Witness: Memory, Representation and the Media in Question, eds. Ulrik 
Ekman and Frederik Tygstrup, 393-413. Copenhagen: Museum Tusculanum Press.

Erll, Astrid. 2008. Cultural Memory Studies: An Introduction. In Cultural Memory

Studies: An International and Interdisciplinary Handbook, eds. Astrid Erll, Ansgar Nünning and Sara B Young, 1-15. Berlin: Walter de Gruyter.

Erll, Astrid and Ann Rigney. 2009. Introduction. In Mediation, Remediation, and the Dynamics of Cutural Memory, eds. Astrid Erll and Ann Rigney, 1-13. Berlin: De Gruyter.

Erll, Astrid. 2011. Memory in Culture. Basingstoke: Palgrave Macmillan.

Fentress, James and Chris Wickham. 1992. Social Memory. Oxford: Blackwell. Halbwachs, Maurice. 1980. The Collective Memory. New York: Harper and Row. Hagedoorn, Berber. 2013. Television as a Hybrid Repertoire of Memory: New Dynamic Practices of Cultural Memory in the Multi-Platform Era. VIEW: Journal of European Television History and Culture vol. 2, no. 3 (European TV Memories): 52-64. Online version: http://www.viewjournal.eu/index.php/ view/article/view/jethc032/60. Last accessed 13. 10. 2017.

Hagedoorn, Berber. 2015. Towards a Participatory Memory: Multi-platform Storytelling in Historical Television Documentary. Continuum: Journal of Media and Cultural Studies vol. 29, no. 4 (New Media, Histories and Memories): 579-592.

Hagedoorn, Berber. 2016. Doing History, Creating Memory: Representing the Past in Documentary and Archive-Based Television Programmes within a MultiPlatform Landscape, Dissertation. Utrecht: Utrecht University.

Hagedoorn, Berber and Bas Agterberg. 2016. The End of the Television Archive as We Know It? The National Archive as an Agent of Historical Knowledge in the Convergence Era. Media and Communication vol. 4, no. 3: 162-175.

Holdsworth, Amy. 2007. Television Resurrections: Television and Memory. Cinema Journal vol. 47, no. 3: 137-144.

Holdsworth, Amy. 2010. Televisual Memory. Screen vol. 51, no. 2: 129-142.

Holdsworth, Amy. 2011. Television, Memory and Nostalgia. Basingstoke, Hampshire: Palgrave Macmillan.

Hoskins, Andrew. 2004. Television and the Collapse of Memory. Time \& Society vol. 13, no. 1: 109-127.

Hoskins, Andrew, ed. 2017. Digital Memory Studies: Media Pasts in Transition. London: Routledge. 
Jönsson, Mats. 2008. Marcimainstream? History in Two Contemporary Swedish TV-Serie. Film International vol. 6, no. 5: 36-41.

Kalinina, Ekaterina. 2014. Multiple Faces of the Nostalgia Channel in Russia. VIEW: Journal of European Television History and Culture vol. 3, no. 5: 52-64. Kompare, Derek. 2002. I've Seen This One Before: The Construction of 'Classic TV' on Cable Television. In Small Screens, Big Ideas: Television in the 1950s, ed. Janet Thumim, 19-34. London: I.B. Tauris.

Kompare, Derek. 2006. Publishing Flow: DVD Box Sets and the Reconception of Television. Television and New Media vol. 7, no. 4: 335-360.

Korteweg, D.A. and P.B. Hugenholtz. 2011. Digitalisering van audiovisueel materiaal door erfgoedinstellingen: Modellen voor licenties en vergoedingen. [Digitization of Audiovisual Material by Heritage Institutions: Models for Licenses and Fees]. Amsterdam: Instituut voor Informatierecht Universiteit van Amsterdam.

Kraak, Haro. Toekomstplannen NPO zeer kritisch ontvangen. de Volkskrant. http://www.volkskrant.nl/media/toekomstplannen-npo-zeer-kritischontvangen a4144984/. Last accessed 18. 09. 2015.

Müller, Eggo. 2012. Televisie in een convergerend medialandschap: 1995-2010. [Television in a Converging Media Landscape: 1995-2010] In Een eeuw van beeld en geluid: cultuurgeschiedenis van radio en televisie in Nederland, eds. Bert Hogenkamp, Sonja de Leeuw and Huub Wijfjes, 274-317. Hilversum: Beeld en Geluid.

Niemeyer, Katharina, ed. 2014. Media and Nostalgia: Yearning for the Past, Present and Future. Basingstoke: Palgrave Macmillan.

Nuchelmans, André. 2014. Publieke omroepen en digitale platformen: Een blik op het verleden en op de toekomst. [Public Broadcasters and Digital Platforms: A Look at the Past and the Future] Boekman no. 98: 32-39.

Nora, Pierre. 1989. Between Memory and History: Les Lieux de Mémoire. Representations no. 26: 7-25.

Plate, Liedeke and Anneke Smelik, eds. 2009. Technologies of Memory in the Arts. Basingstoke: Palgrave Macmillan.

Radstone, Susannah, ed. 2000. Memory and Methodology. Oxford: Berg.

Samuel, Raphael. 1994. Theatres of Memory: Past and Present in Contemporary Culture. London: Verso.

Stelter, Brian. Giddy-up! Seinfeld Is Now Streaming on Hulu, CNN Money, http:// money.cnn.com/2015/06/24/media/hulu-seinfeld/. Last accessed 24. 06. 2015. 
Sobchack, Vivian Carol, ed. 1996. The Persistence of History: Cinema, Television, and the Modern Event. New York: Routledge.

Sturken, Marita. 1997. Tangled Memories: The Vietnam War, the AIDS Epidemic, and the Politics of Remembering. Berkeley: University of California Press.

Sturken, Marita. 2008. Memory, Consumerism and Media: Reflections on the Emergence of the Field. Memory Studies vol. 1, no. 1: 73-78.

Spigel, Lynn. 2005. Our TV Heritage: Television, the Archive, and the Reasons for Preservation. In A Companion to Television, ed. Janet Wasko, 67-99. Oxford: Blackwell Publishing Ltd. 